\title{
SISTEM INFORMASI DATA AKADEMIK SEKOLAH PADA MTS. AL - FURQON BANJARMASIN
}

\author{
Muthia Farida 1), Dian Agustini ${ }^{2)}$ \\ ${ }^{1}$ Fakultas Teknologi Informasi, Universitas Islam Kalimantan \\ Muhammad Arsyad Al Banjari \\ Email : muthiafarida59@gmail.com \\ ${ }^{2}$ Fakultas Teknologi Informasi, Universitas Islam Kalimantan \\ Muhammad Arsyad Al Banjari \\ Email : dian.da989@gmail.com
}

\begin{abstract}
ABSTRAK
Penelitian ini bertujuan untuk membuat sebuah sistem informasi data akademik yang dapat mempermudah pihak sekolah dalam mengelola data akademik sekolah serta mempermudah orang tua murid dalam memantau tumbuh kembang anak disekolah dengan tahapan metode penelitian : 1 . Tahap pengumpulan data yaitu : a) wawancara dengan berkomunikasi secara langsung dengan bagian kepala Sekolah, guru serta tata usaha, b) observasi atau pengamatan langsung, c) studi literatur dengan cara mereview jurnal-jurnal ilmiah, buku atau berbagai sumber yan terkait dengan penelitian yang akan dibuat. 2. Analisi Kebutuhan Sistem. 3. Tahap desain sistem yang menetukan proses dan data yang diperlukan oleh sistem baru. Sistem Informasi data akademik ini menggunakan metode pengujian black box dengan keberhasilan pengujian sistem yang dibuat.
\end{abstract}

Kata Kunci : Blackbox, Data Akademik, Sistem Informasi

\section{PENDAHULUAN}

Pendidikan merupakan salah satu langkah awal bagi seseorang memperoleh kesuksesan. Pendidikan dapat ditempuh disekolah-sekolah sejak usia dini. perbedaan antara masing-masing siswa harus lebih diperhatikan karena perbedaan-perbedaan tersebut dapat menentukan baik buruknya prestasi belajar seorang siswa. Tujuan dasar sekolah adalah mengembangkan semua bakat dan kemampuan siswa, selama proses pendidikan hingga mencapai tingkat yang lebih tinggi. Sekolah MTs Al - Furqon Banjarmasin adalah salah satu sekolah swasta yang tepat bagi orang tua atau masyarakat yang ingin menyekolahkan anaknya untuk lebih mendalami pendidikan agama. Hal ini terlihat dari mata pelajaran yang disajikan setiap semester serta fasilitas mondok bagi siswa siswi dari luar kota. Hal ini membuat sekolah MTs Al - Furqon menjadi salah satu sekolah yang diminati oleh masyarakat. Sekolah MTs Al - Furqon beralamatkan $\begin{array}{llll}\text { dijalan Cemara Ujung RT.15 No.37 } & \text { R }\end{array}$
Banjarmasin dengan jumlah guru sebanyak 60 orang dan jumlah murid sebanyak 640 orang yang terdiri dari kelas VII sebanyak 8 kelas, kelas VIII sebanyak 8 kelas dan kelas IX sebanyak 7 kelas dengan predikat akreditasi A.

Pengelolaan data akademik yang selama ini berjalan pada MTs Al Furqon masih bersifat manual. Hal ini terlihat pada proses pengelolaan data siswa, data guru, data wali kelas, jadwal pelajaran, prestasi siswa, pelanggaran siswa, nilai siswa serta absensi guru dan siswa yang belum terintegrasi dalam sebuah sistem. Hal ini membuat pihak sekolah menjadi kesulitan dalam proses pengelolaan data akademik terutama nilai siswa dari tahun ke tahun. Penelitian ini bertujuan untuk membuat sebuah sistem informasi data akademik yang dapat mempermudah pihak sekolah dalam mengelola data akademik sekolah serta mempermudah orang tua murid dalam memantau tumbuh kembang anak disekolah. 


\section{METODE PENELITIAN}

Metode Penelitian yang dipakai menggunakan Metode Eksperimen dengan Tahapan yang pertama adalah Tahap Pengumpulan Data. Beberapa tahapan dalam pengumpulan data yaitu yang pertama adalah Wawancara yaitu Teknik Pengumpulan data dengan cara berkomunikasi secara langsung dengan kepala sekolah, guru serta tata usaha. Yang kedua adalah Observasi (Pengamatan Langusng) yaitu Teknik pengumpulan data yang dilakukan dengan mengadakan pengamatan secara langsung terhadap sistem yang ada pada MTS Al - Furqon Banjarmasin Dan yang ketiga adalah Studi Literatur yaitu teknik pengumpulan data dengan cara mereview jurnal-jurnal ilmiah, buku dan berbagai sumber refrensi yang terkait tentang penelitian yang akan dibuat.

\section{HASIL DAN PEMBAHASAN}

3.1 Implementasi Sistem yang pertama adalah gambaran dari aplikasi atau program yang telah dibuat.

1. Form Login

Digunakan untuk masuk kedalam sistem. Hanya user tertentu yang dapat masuk kedalam sistem.

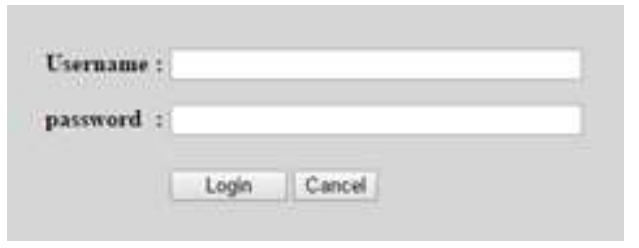

Gambar 1. Halaman Log In

2. Form Siswa

Digunakan untuk menyimpan data siswa.

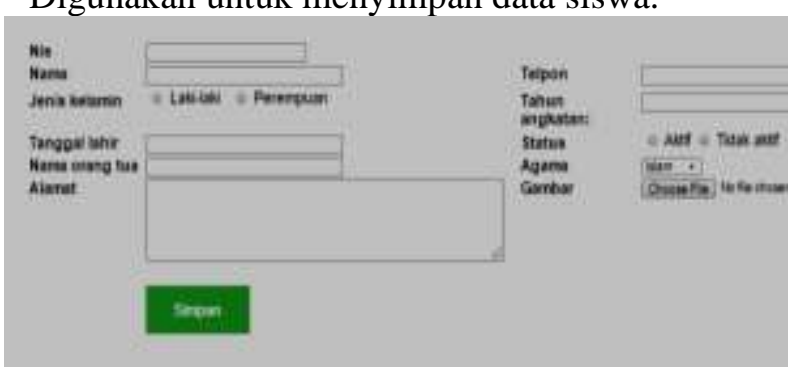

Gambar 2. Form Guru

3. Form Guru

Digunakan untuk menyimpan data

guru.
Selanjutnya adalah Tahap Analisis Kebutuhan Sistem yaitu merupakan kegiatan penguraian suatu sistem informasi yang utuh ke dalam beberapa bagian yang menuntut kita untuk melakukan identifikasi dan evaluasi terhadap permasalahan yang ada dan menentukan kebutuhan sistem dalam rangka mengusulkan perbaikan sistem.

Yang terakhir adalah Tahap Desain Sistem merupakan tahap setelah analisa sistem yang menentukan proses dan data yang diperlukan oleh sistem baru dengan tujuan untuk memenuhi kebutuhan kepada para pemakai, serta memberikan gambaran yang jelas dan rancang bangun yang lengkap kepada pemrogram komputer dan ahli teknik lain yang terlibat.

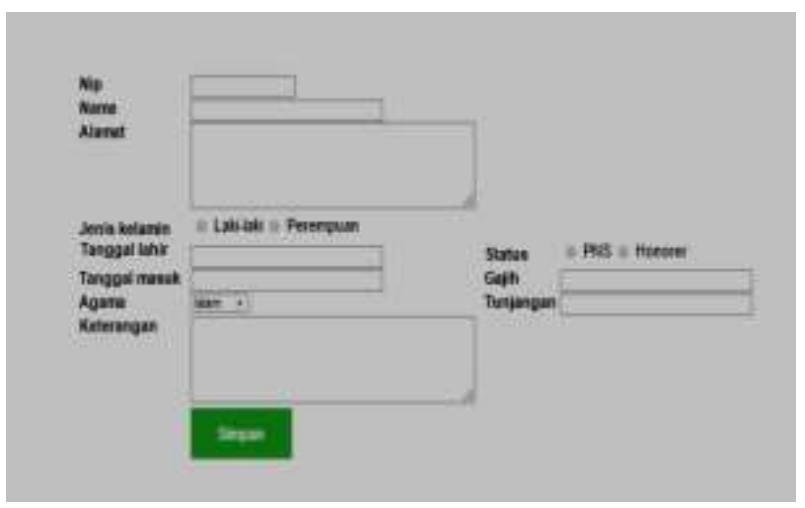

Gambar 3. Form Siswa

4. Form Wali Kelas

Digunakan untuk menyimpan data wali kelas.

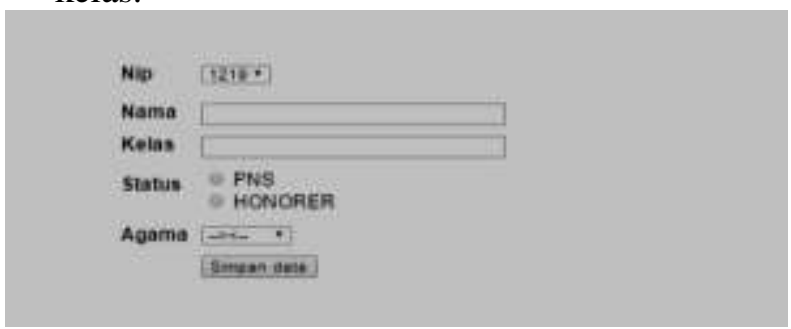

Gambar 4. Form Wali Kelas

5. Form Jadwal Pelajaran

Digunakan untuk menyimpan jadwal pelajaran. 


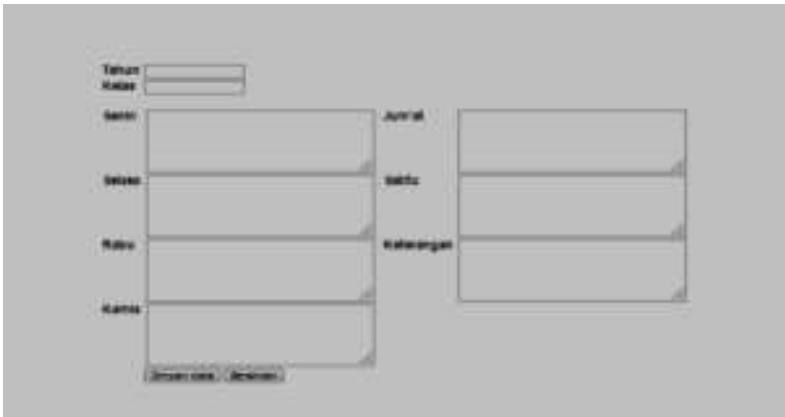

Gambar 5. Form Jadwal Pelajaran

6. Form Prestasi Siswa

Digunakan untuk mengisikan prestasi siswa.

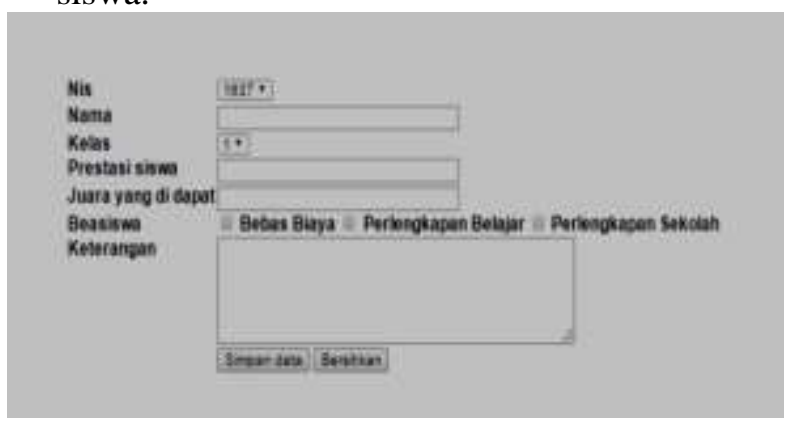

Gambar 6. Form Prestasi Mahasiswa

7. Form Pelanggaran Siswa

digunakan untuk menyimpan data pelanggaran siswa.

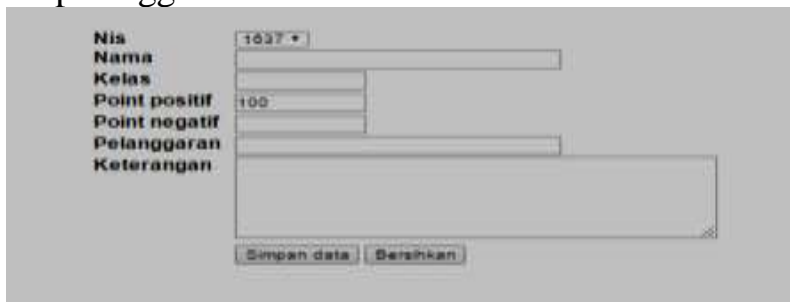

Gambar 7. Form Pelanggaran Siswa

8. Form Nilai Siswa

Digunakan untuk mengisi nilai siswa.

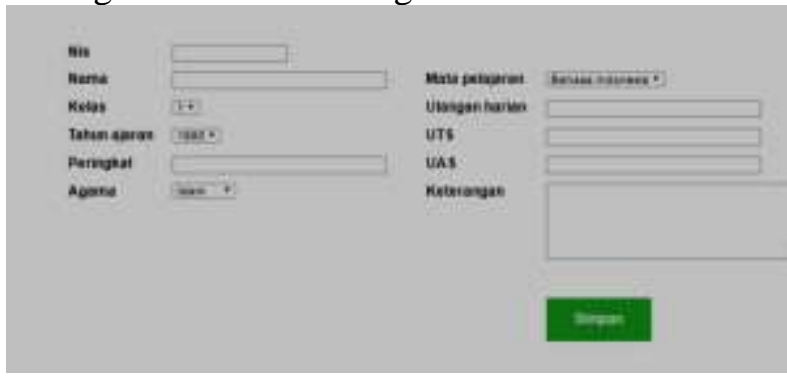

Gambar 8. Form Nilai Siswa

9. Form Absen Guru

Digunakan untuk mengisikan absensi guru.

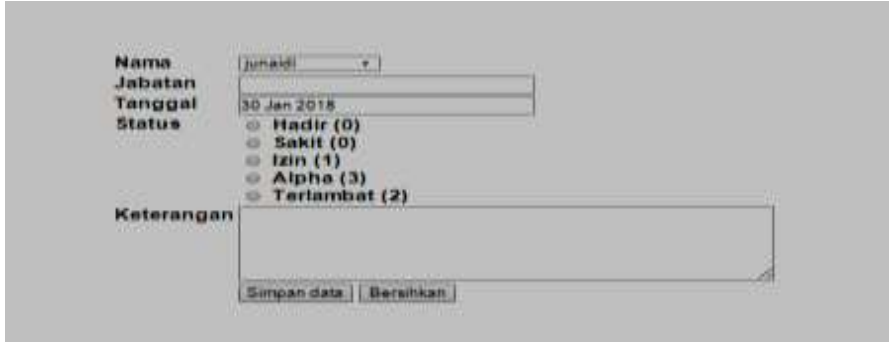

Gambar 9. Form Absen Guru

10. Form Absen Siswa

Digunakan untuk mengisikan absensi siswa.

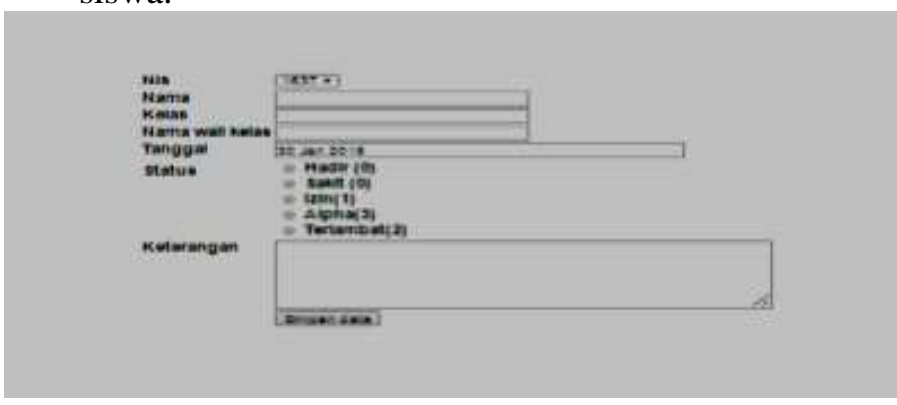

\section{Gambar 10. Form Absen Siswa}

Metode yang di gunakan dalam pengujian ini adalah menggunakan pengujian metode Black Box.

\section{KESIMPULAN}

Dari hasil penelitian yang telah dipaparkan pada bagian sebelumnya, maka dapat disimpulkan bahwa dengan adanya sistem informasi data akademik ini dapat membantu pihak sekolah dalam pengelolaan data-data akademik secara terkomputerisasi serta dengan adanya fitur laporan pada sistem informasi ini dapat mempercepat pihak sekolah dalam proses pencetakan laporanlaporan jika sewaktu-waktu dibutukan.

Adapun saran yang ingin disampaikan pada penelitian ini adalah Laporan data-data akademik sebaiknya dilakukan secara berkala agar pengecekan laporan dapat dilakukan secara maksimal, Sebaiknya diberikan fiture backup database untuk menghindari kerusakan data sewaktu-waktu, Sebaiknya ditambahkan tingkatan hak akses pada saat login sistem. Serta Sebaiknya ditambahkan fitur-fitur yang diperlukan untuk menyempurnakan sistem. 


\section{REFERENSI}

[1] Arief, M. (2011). Pemrograman Web Dinamis Menggunakan Php dan Mysql. ANDI: Yogyakarta.

[2] Arief, M. R. (2011). Pemrograman Web Dinamis menggunakan PHP dan MySQL. Yogyakarta: Andi Publisher.

[3]Hakim, Lukmanul, 2008, Membongkar Trik Rahasia para master PHP, Yogyakarta : Penerbit Lokomedia.
[4] Jogiyanto, H. (2005). Analisis \& Desain Sistem Informasi Pendekatan Terstruktur Teori dan Praktek Aplikasi Bisnis. Yogya: ANDI.

[5]Nugroho, B. (2015). Database Relational dengan MySQL. Yogyakarta: Andi.

[6] Wahana Komputer, 2007 : Konsep Sistem Basis Data dan Implementasinya, Yogjakarta : Graha Ilmu 